\title{
Influence of adenotonsillar hypertrophy on /s/-articulation in children-effects of surgery
}

\author{
Inger Lundeborg Hammarström, Elisabeth Ericsson, \\ Elisabeth Hultcrantz and Anita McAllister
}

\section{Linköping University Post Print}

N.B.: When citing this work, cite the original article.

Original Publication:

Inger Lundeborg Hammarström, Elisabeth Ericsson, Elisabeth Hultcrantz and Anita McAllister, Influence of adenotonsillar hypertrophy on /s/-articulation in children-effects of surgery, 2011, Logopedics, Phoniatrics, Vocology, (36), 3, 100-108.

http://dx.doi.org/10.3109/14015439.2010.531047

Copyright: Informa Healthcare http://informahealthcare.com/

Postprint available at: Linköping University Electronic Press http://urn.kb.se/resolve?urn=urn:nbn:se:liu:diva-61244 


\title{
Influence of adenotonsillar hypertrophy on s-articulation in children - Effects of surgery.
}

\author{
Inger Lundeborg $^{1}$, Elisabeth Ericsson ${ }^{2,3}$, Elisabeth Hultcrantz ${ }^{2}$ \& Anita McAllister ${ }^{1}$
}

Department of clinical and experimental medicine, ${ }^{1}$ Division of speech and language

pathology, ${ }^{2}$ Division of Oto-rhino-laryngology, Linköping University, Sweden, ${ }^{3}$ Department of Nursing Science, School of Health Sciences, Jönköping, Sweden

Corresponding author: Inger Lundeborg, Department of clinical and experimental medicine, Linköping University, S-581 85 Linköping, Sweden. Phone +4613221287 Fax: +4513222504 E-mail: Inger.lundeborghammarstrom@liu.se

\section{Key words}

child, s-articulation, adeno-tonsillar hypertrophy, perceptual and acoustic evaluations, 


\section{Abstract}

Tonsillar hypertrophy is common in young children and affects several aspects of the speech such as distortions of the dento-alveolar consonants. The study objective was to assess sarticulation, perceptually and acoustically in children with tonsillar hypertrophy and compare effects of two types of surgery, total tonsillectomy and tonsillotomy. Sixty-seven children, 5065 months, on waiting list for surgery, were randomized to tonsillectomy or tonsillotomy. The speech material was collected pre-operatively and six months post-operatively. Two groups of age-matched children were controls. /S/-articulation was affected acoustically with lower spectral peak locations and perceptually with less distinct /s/-production before surgery, in comparison to controls. After surgery /s/-articulation was normalized perceptually, but acoustic differences still remained. No significant differences between surgical methods were found..

\section{Introduction}

Human speech is an extremely complex motor behaviour requiring coordinated control of several muscles and muscle movements (Abbs and Gracco, 1984; Forrest, 2002). The normal development of speech and language during childhood is dependent on several properties in the environment and innate abilities of the child (Schiff-Myers, 1998). There are several obvious physical conditions that can impair speech development in children, among them structural abnormalities of the articulators in the oral cavity. The physiological hypertrophy of tonsils and adenoids during childhood can be such an alteration that may affect the speech. Problems with articulation of dento-alveolar consonants and voice resonance have been previously reported (Ahlqvist-Rastad, Hultcrantz, and Svanholm, 1988; Maryn, Van Lierde, 
De Bodt, and Van Cauwenberge, 2004; Mora, Crippa, Dellepiane, and Jankowska, 2007; Salami, Jankowska, Dellepiane, Crippa, and Mora, 2008). The prevalence of speech and voice disorders in children with hypertrophic tonsils is still somewhat unclear but in a study by Salami and colleagues (2008) the reported deviant /s/-production was 42,5\% preoperatively. Hypertrophic tissue has a dampening effect causing deterioration of quality and precision of speech output. This dampening effect can be measured using the noise to harmonic ratio (NHR) (Salami et al., 2008). As a consequence of a reduced oropharyngeal space the affected children drop the mandible and tongue to maximize the oral airway. This affects the craniofacial development and cause deviations of the dental occlusion with a significantly more open intermaxillary jaw relationship, retrognathic inclined mandible, lateral cross-bite and narrower inter-canine width when compared to healthy controls (Behlfelt, LinderAronsson, McWilliam, Neander, and Laage-Hellman, 1990; Lofstrand-Tidestrom, Thilander, Ahlqvist-Rastad, Jakobsson, and Hultcrantz, 1999). In a recent study from Finland the prevalence of Class II or asymmetric malocclusion in children with sleep-disordered breathing was 33\% (Pirilä-Parkkinen, Pirttiniemi, Nieminen, Tolonen, Pelttari, and Löppönen, 2009) An open-bite may cause distortions of the s- sound normally produced by the tip of tongue in the dentoalveolar region (Laine, 1987). Normal /s/ is produced by many individuals with a low tongue tip and the tongue blade at the site of maximum contriction which is consistently in the region mentioned. Distortion of the sibilant s-sound has frequently been reported in speakers with malocclusion, presumably because s-production requires a very precise placement of the articulators (Lee, Whitehill, Ciocca, and Samman, 2002). In Swedish, s is produced with the tongue tip on the lower (with the upper surface of the tonguetip on the alveolar ridge, in $60 \%$ of all speakers ) or upper incisors (in $40 \%$ of all speakers) (Lindblad and Lundqvist, 1996). The lateral margins of the tongue are adapted to the alveolar process and the current of air is directed by a short midsagittal groove of the tongue to the 
incisors (Lindblad, 1980). The principal sound source is produced when the airstream strikes the teeth (Ladefoged and Maddieson, 1996; Lindblad, 1980). The resonance cavity anterior to the midsaggital tongue groove is of particular importance to the quality of the /s/-sound (Lindblad, 1980) . This delicate oral motor control is one of the most difficult aspects of speech production (Niemi, Laaksonen, Ojala, Aaltonen, and Happonen, 2006) and demand a great degree of articulatory precision. A variation of one millimetre in the position or shape of the articulators makes a great difference in the acoustic result (Ladefoged and Maddieson, 1996). This corresponds to the quantal theory of critical areas in the vocal tract first described by Stevens 1972 . The adult sibilant/s/-sound is produced with a short anterior cavity and therefore display spectral peaks at higher frequencies (around $5 \mathrm{kHz}$ ) in comparison to the more posterior alveolo-palatal fricative with spectral peaks at about $3 \mathrm{kHz}$ (Lindblad, 1980). Women and children display higher spectral peaks then men reflecting their smaller dimensions of the vocal tract and oral cavity (Daniloff, Wilcox, and Stephens, 1980).When comparing acoustic data from adult sibilant production with children's, it has been found that the articulatory gestures of children are not as precisely specified as those of adults (Nittrouer, 1995). Most Swedish children have the /s/-sound in their phonemic inventory by the age of four, but before the age of six years /s/-sound production is often variable (Nettebladt, 2007) and incorrect production of the Swedish sibilant fricatives is the most common articulatory deviation in Swedish children (Öster, House, Hatzis, and Green, 2003). When studying speech production errors perceptual evaluations are widely used (Lohmander and Olsson, 2004). Perceptual judgements may be supplemented by acoustic analysis. Acoustic analysis can measure distortions of fricatives that may be difficult to reliably document perceptually (Lee et al., 2002). A speech disorder can also have other negative effects on a child's life. Several studies have shown that teachers have negative attitudes towards children with articulation (Overby, 
Carrell, and Bernthal, 2007; Ruscello, Stutler, and Toth, 1983) or voice disorders (Sederholm, McAllister, Dahlkvist and Sundberg, 1995). A reduced quality of life is reported in children with tonsillar hypertrophy with emotional distress, reduced daytime functioning and a high degree of concern in caregivers apart from the sleep disturbance compared with controls (Ericsson, Lundeborg and Hultcrantz, 2009).

Children with adenotonsillar hypertrophy are usually treated with adenoidectomy and tonsil surgery, which is the operation most frequently performed in children (Koempel, Solares, and Koltai, 2006; Younis and Lazar, 2002). With regard to surgical methods, two principals are currently adapted to operate on the tonsils: Tonsillectomy is the most common, whereby a total removal of the tonsils is done. However tonsillectomy is associated with a high degree of post-operative pain that is difficult to control and also with a risk for severe post-operative bleeding (Koempel et al., 2006). Another surgical method is tonsillotomy, where the hypertrophicobstructive tissue is removed leaving a normal sized tonsil within the tonsillar pouch (Densert et al, 2001; Hultcrantz and Ericsson, 2004; Hultcrantz, Linder and Markström, 2005). Studies have shown that tonsillotomy gives lower primary morbidity with less postoperative pain in comparison with tonsillectomy and the long-term effects against both snoring and infections are equal (Anand, Vileda, and Linde Guarisco, 2005; Ericsson, Graf, and Hultcrantz, 2006; Koempel et al., 2006). The question is whether tonsillotomy gives equal improvement also on other functional aspects that may be affected by adenotonsillar hypertrophy?

In a previous investigation on the same material we found that oral motor function regarding non speech activities was hampered in children with tonsillar hypertrophy and normalized after surgery (Lundeborg, McAllister, Graf, Ericsson, and Hultcrantz, 2009). The study also revealed some minor sex differences with the boys having somewhat larger problems before surgery than girls. The aim of the present study is to investigate whether /s/-articulation is 
affected in the same 4-5 years old children with adenotonsillar hypertrophy and compare the effects of surgery with either tonsillectomy or tonsillotomy in comparison to age matched controls.

\section{Methods}

The study was approved by the Medical Ethics Committee of Linköping University on 200311-04 (No 03-448).

A total of 118 children with adenotonsillar hypertrophy on the waiting list for surgery from three clinics in the south-east region of Sweden were initially randomized to either tonsillectomy or tonsillotomy according to the method of Zelen (Zelen, 1981). The families were invited to participate after they had received written information of the study and the surgery their child would undergo. Thirty-seven families declined participation (23 tonsillectomy and 14 tonsillotomy). Ten children were excluded in accordance with the exclusion criteria: treated tonsillitis within three months prior to the planned operation, spontaneous recovery from an earlier obstruction, concomitant disease or non-Swedish speaker. Four children were excluded due to randomization error.

A total of 67 children (33 tonsillectomy and 34 tonsillotomy), aged 4 years, 2 months to five years, 5 months months (mean age of 4 years, 9 months) at the pre-operative assessment, and consisting of 28 girls and 39 boys were included in the study. Six of these children had previously undergone a separate adenoidectomy. None of the participating children had any speech or language therapy prior to the study. Six of the children had otitis media with effusion at the preoperative examination with need for grommet insertion. All other children had normal ear conditions and no record of hearing problems (Lundeborg, McAllister, Samuelsson, Ericsson, and Hultcrantz, 2009). All children in the tonsil group but four had front incisors preoperatively. Postoperatively all but 10 had deciduous front teeth or erupting 
permanent incisors at various stages. Seventy pre-school children, aged 4 years, 1 month to 5 years, 11 months months from the same area as the surgical groups were selected to be controls to the study-groups. Inclusion criteria for controls were no history of adenotonsillar problems, no recurrent ear infections and no speech and language pathology contacts. No assessment of articulation was made prior to the inclusion. Thirty-five of them, aged 4years, 1 month to five years 5 months (mean age of 4 years, 9 months), served as controls for comparisons before surgery ('younger control group'), and 35, aged five years, six months to five years, 11 months ( mean age 5 years, 8 months), served as controls for comparison after surgery ('older control group'), see table 1. In the younger controls all children but one had front incisors and in the older group all but two had front incisors.

\section{Table 1.}

Number of boys and girls and mean age of participants and controls at the speech assessments before and after surgery

\begin{tabular}{|c|c|c|c|c|c|}
\hline \multicolumn{2}{|c|}{$\begin{array}{l}\text { Randomized for } \\
\text { tonsillectomy }\end{array}$} & \multicolumn{2}{|c|}{$\begin{array}{c}\text { Randomized for } \\
\text { tonsillotomy }\end{array}$} & \multicolumn{2}{|c|}{ Controls } \\
\hline $\begin{array}{l}\text { Preop } \\
(n=33)\end{array}$ & $\begin{array}{l}\text { Postop } \\
(\mathrm{n}=32)\end{array}$ & $\begin{array}{l}\text { Preop } \\
(\mathrm{n}=34)\end{array}$ & $\begin{array}{l}\text { Postop } \\
(\mathrm{n}=33)\end{array}$ & $\begin{array}{l}\text { Younger } \\
(n=35)\end{array}$ & $\begin{array}{l}\text { Older } \\
(\mathrm{n}=35)\end{array}$ \\
\hline$+11 \partial^{\lambda} 22$ & + $11 \mathrm{O}^{\top} 21$ & †17 & ○17 & 우14 ふ21 & 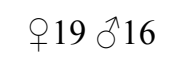 \\
\hline $4 ; 10$ years & $5 ; 6$ years & $4 ; 9$ years & $5 ; 5$ years & $4 ; 9$ years & $5 ; 8$ years \\
\hline
\end{tabular}

At the pre-surgical assessment, all 67 children in the study group and the 35 controls participated. All operated children except one in each study-group (65) came to a follow-up visit after approximately six months (mean age 5 years, 5 months). A 'post operative' control group consisting of 35 children, was also assessed. All children did not participate in all tasks, see table 2 
Table 2.

Number of children in the study and participating in the different tasks

\begin{tabular}{|c|c|c|c|c|}
\hline & $\begin{array}{l}\text { Preop studygroup } \\
n=67\end{array}$ & $\begin{array}{l}\text { Postop studygroup } \\
n=65\end{array}$ & $\begin{array}{l}\text { Younger controls } \\
n=35\end{array}$ & $\begin{array}{c}\begin{array}{c}\text { Older controls } \\
\mathrm{n}=35\end{array} \\
\text { - }\end{array}$ \\
\hline $\begin{array}{l}\text { Material for the } \\
\text { perceptual } \\
\text { evaluation }\end{array}$ & $n=61$ & $\mathrm{n}=62$ & $\mathrm{n}=35$ & $\mathrm{n}=34$ \\
\hline $\begin{array}{l}\text { Material for the } \\
\text { acoustic } \\
\text { analysis }\end{array}$ & $\mathrm{n}=45$ & $\mathrm{n}=57$ & $\mathrm{n}=35$ & $\mathrm{n}=32$ \\
\hline
\end{tabular}

\section{Surgery}

Thirty-three children were randomized for tonsillectomy, and 34 for tonsillotomy. Twentyfive of thirty-three children in the tonsillectomy group and 28/34 children in the tonsillotomy group were also planned for adenoidectomy during the same surgery session. Six children with otitis media with effusion (OME), three in each group were planned for grommet insertion. The decision on grommet insertion was based on the ENT-examination and medical history taken before surgery. Formal hearing tests were not included.

\section{Assessments procedure}

Within a month before surgery, speech samples from the children in the two study groups, were elicited by picture naming and sentence repetition. In some cases the word associated with the picture was elicited by repetition. The criteria for the words chosen were that they should be well-known to most children and include /s/ in conjunction with a high vowel. The sentence was composed so that the /s/-sound occurred in word initial as well as word medial and word final position ('Sissi och Lasse sover i sitt hus').The children were allowed to make as many trials as needed to get the whole sentence recorded. The speech samples were audiorecorded using a Marantz PMD 660 Professional Recorder with a sampling frequency of 44.1 $\mathrm{kHz}$ and an Audiotechnica mb microphone at a distance of approximately $60 \mathrm{~cm}(23.5 \mathrm{inch})$ 
from the child. Those receiving surgery were recorded again six months postoperatively. The younger and older control groups were recorded once.

\section{Analysis}

A perceptual analysis of the /s/-sound was made independently by three trained speech and language pathologists (SLP) blinded with respect to surgical method and pre- or postoperative or control status. The analysis was performed on a predetermined form with Visual Analogue Scales (VAS). The end-points were 'A sharp and distinct /s/-sound' $(0 \mathrm{~mm})$ and 'Very deviant and indistinct /s/-sound' $(100 \mathrm{~mm})$. The raters were also asked to tick whether they considered the overall /s/-production as normal or deviant.

Inter-rater agreement was calculated with Cronbach's Alfa. A random selection of $10 \%$ of the recordings were copied and mixed with the material in order to determine intra-rater agreement, also calculated with Cronbach's Alfa.

Three /s/-sounds in three word positions, initial, medial and final, in conjunction with high vowels (in the words 'Sissi' and 'hus'), were also analyzed acoustically using the Praat software (http:www.fon.hum.uva.nlpraat Version 5.1.31, Paul Boersma and David Weenink, Phonetic Sciences Department, University of Amsterdam) Segmentation of the onset and offset of the target sound was conducted with inspection of the waveform and wideband spectrogram according to the method described by Jongman, Wayland and Wong (Jongman, Wayland, \& Wong, 2000). The onset was defined as the point where the high frequency energy first appeared (also characterized by a rapid increase of zero-crossings) and the offset was determined by the intensity minimum prior to the onset of the vowel periodicity. The noise duration (the duration of the /s/-sound), defined as the time from onset to offset was calculated by the Praat software. Spectral peak estimation was made from a LTAS of the target sound defined as above. 


\section{Statistical analysis}

Demographic data were expressed with descriptive statistics. Differences between the groups, including sex-differences, were analyzed using the Mann-Whitney $U$-test both for perceptual ratings and acoustic data. Changes before and after surgery within the study groups were analyzed using the Wilcoxon signed-rank test. Correlation analysis was made between the perceptual evaluations of /s/-articulation and acoustic measures using Spearman's rank correlation coefficient. $P$-values $<0.05$ were considered statistically significant. The statistical analyses were performed using SPSS $\odot$ Windows version 17.0.

\section{Results}

The children's surgery was performed by the clinic's otolaryngologist specialized regarding the surgical procedure and according to the randomization. No post-operative complications were reported. Adenoidectomy and grommet insertion was performed in all planned cases.

\section{The perceptual analysis}

The perceptual analysis of the /s/-sound at the preoperative assessment did not show any difference between the tonsillectomy- and the tonsillotomy-group. Compared to the agematched controls, the tonsillectomy- and tonsillotomy-groups together differed significantly $(\mathrm{p}<0.01)$ with higher mean ratings on VAS. See table 3.

The statistical analysis of the perceptual evaluation six months after surgery did not show any significant improvement compared to the pre-operative ratings. The operated children did not differ significantly from the older controls, neither as a whole group nor when divided according to surgical methods. There were no significant differences between the assessments 
of the /s/-sounds of the children operated with tonsillectomy and the children operated with tonsillotomy.

\section{Table 3.}

Perceptual analysis with VAS for study groups and controls expressed in average scores.

\begin{tabular}{lccc}
\hline & Tonsillectomy+tonsillotomy & Controls & $\begin{array}{c}\text { P- } \\
\text { value* }^{*}\end{array}$ \\
\hline $\begin{array}{l}\text { Preop } \\
\text { Tonsillectomy+Tonsillotomy/younger }\end{array}$ & $27.2 \pm 18.8^{\text {a) }}$ & $17.3 \pm 9.3$ & \\
$\begin{array}{l}\text { control group } \\
\text { Postop }\end{array}$ & $\mathrm{n}=61$ & $\mathrm{n}=35$ & $<0.01$ \\
$\begin{array}{l}\text { Tonsillectomy+Tonsillotomy/older } \\
\text { control group }\end{array}$ & $23.5 \pm 18.2^{\text {a) }}$ & $19.8 \pm 10.6$ & \\
\hline \hline
\end{tabular}

VAS $=$ Visual Analogue Scale $(0-100 \mathrm{~mm}){ }^{\mathrm{a})}$ Mean \pm SD *Mann Whitney U-test

There were no significant differences between the younger and the older control groups.

Following a procedure developed by Sederholm et al. (Sederholm, McAllister, Sundberg, and Dahlqvist, 1993), the mean ratings for each child was plotted in rank order for each group separately. The graphs exhibit a discontinuity (an 'elbow') at approximately $25 \mathrm{~mm}$ VAS for all groups, see figure 1 . This discontinuity served as an operational definition with deviant /s/sound production above the borderline. According to this definition $39 \%$ of the study group before surgery and $27 \%$ after surgery had deviant/s/-sounds, compared to $25.7 \%$ of the younger controls and $17.6 \%$ of the older controls, see figure 1. When comparing this borderline with the SLP's overall deviancy-ratings, all children above $25 \mathrm{~mm}$ VAS but four were rated as deviant.

There were no significant sex-differences in the study groups before surgery but after surgery girls were rated to have more distinct s-sounds than boys $(\mathrm{p}<0.05)$. The same sex difference was found in both control groups ( $\mathrm{p}<0.05$ for both groups). 


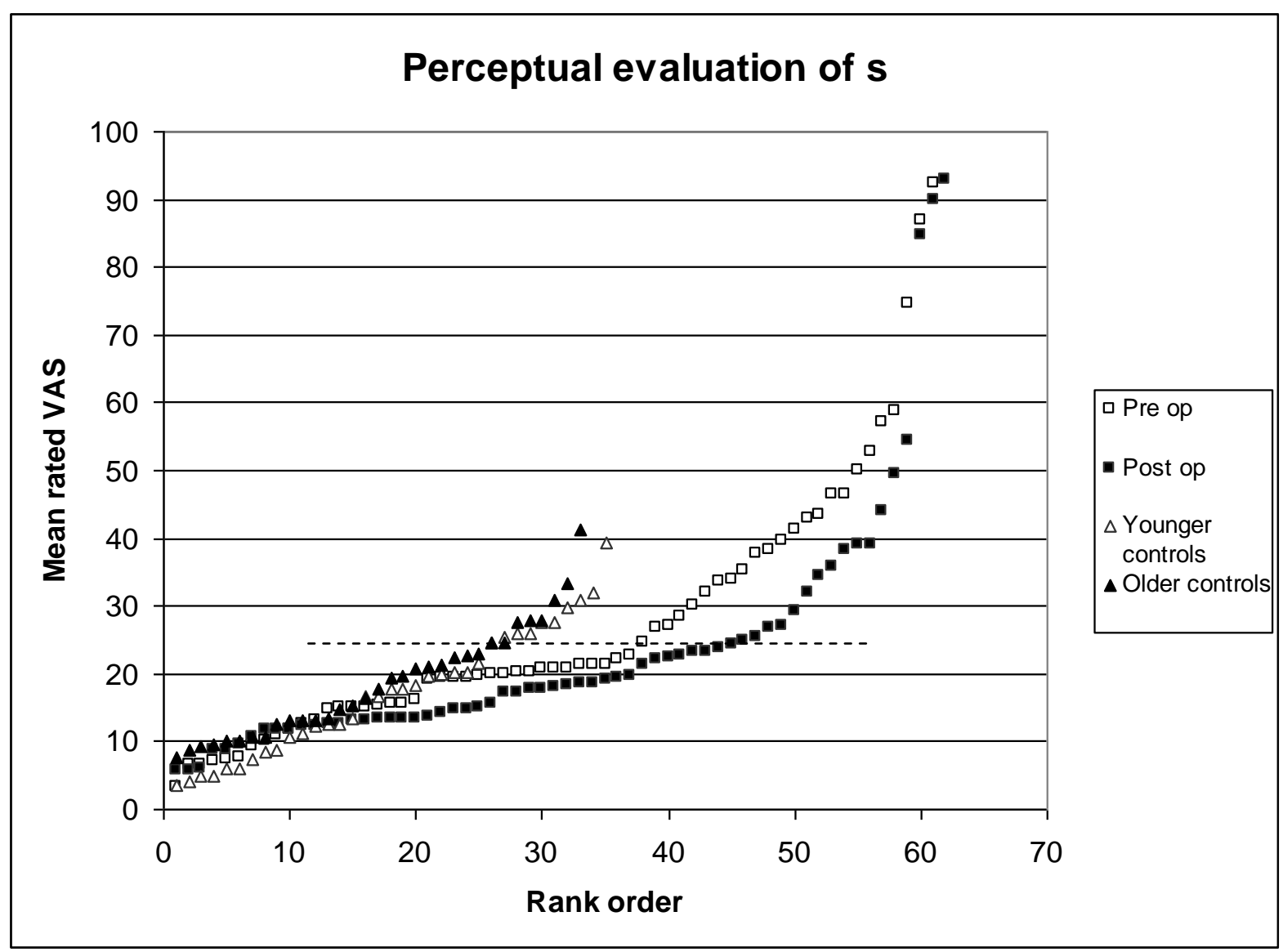

Figure 1. Mean VAS-ratings plotted in rank order, dotted line at the discontinuity at approximately $25 \mathrm{~mm}$

Inter-rater reliability calculated with Cronbach's Alfa was found to be 0.81 and intra-rater reliability found to be $0.97,0.73$ and 0.65 for the three listeners respectively.

\section{The acoustic analysis}

Pre-operative results:

The acoustic analysis did not demonstrate any significant differences between the tonsillectomy- and the tonsillotomy-groups at the pre-operative assessment. Compared to the controls, the children in the study-groups together differed significantly $(\mathrm{p}<0.05)$ with respect to peak location-values at the preoperative assessment. This difference was not seen regarding 
the noise duration of the /s/-sound. There were no sex differences found within or between groups. See table 4 and 5.

Post-operative results:

Six months after surgery the study groups differed significantly from the older control group with respect to noise duration $(\mathrm{p}<0.0001)$ and peak locations $(\mathrm{p}<0.001)$ showing that noise duration was significantly longer and the peak location significantly higher in the study groups. The same difference was seen with the younger controls having significantly longer noise duration and higher peak locations than the older control group $(\mathrm{p}<0.0001$ for both values), see table 4 and 5. A longer noise duration was seen in girls compared to boys in the study groups $(\mathrm{p}<0.05)$. The results were not affected by excluding the children with absent incisors.

There was no significant difference between the two study groups regarding noise duration or peak location. There were no significant differences between the preoperative and postoperative values for the study groups.

A significant negative correlation ( Spearman's rho -0,405) was found between the perceptual ratings and the peak location values of the studygroups $(\mathrm{p}<0.001)$. No significant correlation was found between perceptual ratings and noise duration

\section{Discussion}

The results of this study show that the /s/-articulation of children with tonsillar hypertrophy is affected with significantly lower spectral peak frequencies than in controls. This difference is also reflected in the results of the perceptual analysis made by the experienced listeners who judged the /s/-sounds of the children in the study groups to be significantly less distinct than those of the controls. These results can be explained by the oral motor problems that children 
Table 4.

Noise Duration values in word initial, medial and final position for study groups and controls.

\begin{tabular}{|c|c|c|c|c|c|c|}
\hline & $\begin{array}{c}\text { ND initial } \\
\text { sec }^{\text {a) }}\end{array}$ & $\begin{array}{c}\text { P- } \\
\text { value }\end{array}$ & $\begin{array}{c}\text { ND medial } \\
\sec ^{\text {a) }}\end{array}$ & $\begin{array}{c}\text { P- } \\
\text { value }\end{array}$ & $\begin{array}{c}\text { ND final } \\
\text { sec }^{\text {a) }}\end{array}$ & $\begin{array}{c}\text { P- } \\
\text { value }\end{array}$ \\
\hline TE/TT preop & $0.17 \pm 0.02 / 0.13 \pm 0.01$ & $\mathrm{~ns}^{*}$ & $0.23 \pm 0.02 / 0.22 \pm 0.02$ & ns* & $0.17 \pm 0.02 / 0.20 \pm 0.02$ & ns* \\
\hline TE+TT preop / younger controls & $0.15 \pm 0.01 / 0.13 \pm 0.01$ & $\mathrm{~ns}^{*}$ & $0.22 \pm 0.01 / 0.24 \pm 0.01$ & ns* & $0.20 \pm 0.02 / 0.15 \pm 0.01$ & $<0.01 *$ \\
\hline TE/TT postop & $0.13 \pm 0.01 / 0.12 \pm 0.01$ & $\mathrm{~ns}^{*}$ & $0.21 \pm 0.01 / 0.2 \pm 0.01$ & $\mathrm{~ns}^{*}$ & $0.17 \pm 0.01 / 0.17 \pm 0.01$ & $\mathrm{~ns}^{*}$ \\
\hline TE+TT preop / TE+TT postop & $0.15 \pm 0.01 / 0.12 \pm 0.01$ & $\mathrm{~ns}^{\nabla}$ & $0.22 \pm 0.01 / 0.20 \pm 0.01$ & $\mathrm{~ns}^{\nabla}$ & $0.20 \pm 0.02 / 0.17 \pm 0.01$ & $\mathrm{~ns}^{\nabla}$ \\
\hline TE+TT postop / older controls & $0.12 \pm 0.01 / 0.10 \pm 0.01$ & $<0.05 *$ & $0.20 \pm 0.01 / 0.16 \pm 0.01$ & $<0.01 *$ & $0.17 \pm 0.01 / 0.11 \pm 0.01$ & $<0.0001 *$ \\
\hline Younger controls / older controls & $0.13 \pm 0.01 / 0.10 \pm 0.01$ & $<0.01 *$ & $0.24 \pm 0.01 / 0.16 \pm 0.01$ & $<0.0001 *$ & $0.15 \pm 0.01 / 0.11 \pm 0.01$ & $<0.05^{*}$ \\
\hline
\end{tabular}

Table 5.

Peak Location- values in initial, medial and final position for study groups and controls expressed in average scores.

\begin{tabular}{|c|c|c|c|c|c|c|}
\hline & $\begin{array}{c}\text { PL initial } \\
\mathrm{Hz}^{\text {a) }}\end{array}$ & $\begin{array}{c}\mathbf{P}- \\
\text { value }\end{array}$ & $\begin{array}{c}\text { PL medial } \\
\mathrm{Hz}^{\text {a }}\end{array}$ & $\begin{array}{c}\mathbf{P}- \\
\text { value }\end{array}$ & $\begin{array}{c}\text { PL final } \\
\mathrm{Hz}^{\text {a) }}\end{array}$ & $\begin{array}{c}\text { P- } \\
\text { value }\end{array}$ \\
\hline TE/TT preop & $6154 \pm 618 / 6674 \pm 667$ & $\mathrm{~ns}^{*}$ & $6674 \pm 598 / 6087 \pm 529$ & $\mathrm{~ns}^{*}$ & $5635 \pm 583 / 6297 \pm 787$ & $\mathrm{~ns}^{*}$ \\
\hline $\begin{array}{l}\text { TE+TT preop / } \\
\text { younger controls }\end{array}$ & $6450 \pm 446 / 7673 \pm 356$ & $<0.05 *$ & $6374 \pm 396 / 7761 \pm 341$ & $<0.01 *$ & $6027 \pm 519 / 6658 \pm 359$ & ns* \\
\hline TE / TT postop & $6763 \pm 404 / 5923 \pm 629$ & $\mathrm{~ns}^{*}$ & $6912 \pm 546 / 7477 \pm 494$ & $\mathrm{~ns}^{*}$ & $5293 \pm 428 / 5739 \pm 391$ & $\mathrm{~ns}^{*}$ \\
\hline $\begin{array}{l}\text { TE+TT preop / } \\
\text { TE+TT postop }\end{array}$ & $6450 \pm 440 / 6343 \pm 375$ & $\mathrm{~ns}^{\nabla}$ & $6374 \pm 396 / 7229 \pm 365$ & $\mathrm{~ns}^{\nabla}$ & $6027 \pm 519 / 5527 \pm 287$ & $\mathrm{~ns}^{\nabla}$ \\
\hline $\begin{array}{l}\text { TE+TT postop / } \\
\text { older controls }\end{array}$ & $6343 \pm 375 / 5134 \pm 397$ & ns* & $7229 \pm 665$ / $5255 \pm 352$ & $<0.0001 *$ & $5527 \pm 287 / 4946 \pm 308$ & $\mathrm{~ns}^{*}$ \\
\hline $\begin{array}{l}\text { Younger controls } \\
\text { /older controls }\end{array}$ & $7673 \pm 356 / 5134 \pm 397$ & $<0.001 *$ & $7761 \pm 341 / 5255 \pm 352$ & $<0.0001 *$ & $6658 \pm 359 / 4946 \pm 308$ & $<0.01 *$ \\
\hline
\end{tabular}

TE $=$ Tonsillectomy TT=Tonsillotomy ${ }^{a)}$ Mean \pm SD $*$ Mann Whitney U-test ${ }^{\nabla}$ Wilcoxon's signed rank test 
with tonsillar hypertrophy experience (Lundeborg, McAllister, Graf et al., 2009). The production of the /s/-sound, with its demands on precise placements of the articulators, especially the tongue seems to be vulnerable to the structural alteration of the oral cavity that hypertropic tonsils cause. In /s/-production the resonance cavity anterior to the midsaggital groove in the tongue is of particular importance to the sound quality (Lindblad, 1980). Several studies have shown that maxillar growth as well as dental arch morphology is affected by tonsillar hypertrophy (Lofstrand-Tidestrom and Hultcrantz, 2009; Lofstrand-Tidestrom et al., 1999). This can be a possible explanation to some of the speech problems that have been reported in connection to tonsillar hypertrophy. /s/-production is also dependant on a normal hearing in the higher frequency area. In the present study a formal hearing test was not included, instead a thorough patient history including questions about hearing was made during the preoperative ENT examination. Only six children had otitis media with effusion (OME) and had grommets inserted at surgery. However, it can not be ruled out that also other children had earlier had periods of OME and short term compromised hearing. However, this is equally probable for the children in the control groups. The incidence of OME in children aged five to six is about $15-17 \%$, but most of these children are only affected for shorter periods (Midgley, Dewey, Pryce, and Maw, 2000; Williamson, Dunleavey, Bain, and Robinson, 1994) and there are no studies showing that shorter periods of OME influence speech development.

When comparing pre- and postoperative data of the study groups the /s/-articulation did not improve significantly for the whole group. There was a large variability particularly in the study groups but the general trend found was towards a more normal sounding /s/-production according to the perceptual evaluations illustrated in figure 1. A comparison of post operative acoustic values showed that noise duration was significantly longer and peak location significantly higher in the study groups even though the previous study on the same material 
found normalized non speech oral motor function (Lundeborg et al., 2009). One possible explanation for remaining acoustic differences could be that the children in the study groups still six months post-operatively habitually used more effort than the controls in their speech production. It has been hypothesized in speech production models that the speaker does not put in more effort than needed to be interpreted by the listener (Lindblom, 1990). This delicate balance between speech effort and articulatory economy based on the speaker's assumption regarding the listener's needs is gradually being more refined during childhood. This is in line with the important steps in the development of theory of mind and self control that children seem to achieve after the age of four (Perner and Lang, 1999). The influence on the articulation by the enlarged tonsils, can possibly be the cause of the difference between the study groups postoperatively and the corresponding controls. A six-month period is probably too short to change these articulatory details. The fact that this difference also was seen when younger and older controls were compared can possibly be explained by this developmental aspect.

These acoustic differences were not perceived by the listeners perhaps due to their listening to a larger material and not focusing specifically on /s/-production in relation to higher vowels. Another possible explanation could be there perhaps is a perceptual tolerance for variation in children. An important finding was that the /s/- production of the post-operative study-group was perceived as age-appropriate. This is in line with the changed position of observed elbow in the rank ordered graph for the individual mean ratings indicating lower mean ratings post surgically. However statistical significance was not reached. This can probably be explained by a few outliers with highly deviant/s/-production also at the postoperative assessment. A distorted s-production may affect speech clarity since the /s/-sound is one of the most common speech sounds in Swedish. Studies have shown that teachers' attitudes towards affected children are more negative than toward normal speaking children (Overby et al., 
2007; Ruscello et al., 1983). In this study, experienced speech language pathologists were used for the perceptual evaluation. Had naïve listeners instead been used, the results would perhaps have been different, as shown in a previous study (Lundeborg and McAllister, 2007). In that investigation a combination of experienced and naïve listeners were used as raters of intelligibility. The SLP's were significantly better than the naïve listeners at hearing the target sounds and words. Perhaps this difference reflects the SLP's background of having heard many children with speech difficulties thus improving their capacity to fill-in missing speech sounds. It is probable that the regular perceptual assessment used in daily SLP-practice make SLP's more observant also of minor differences in speech production compared to naïve listeners (Witt, Berry, Marsh, Grames, and Pilgram, 1996).

In this study the participating girls were perceived as having more distinct s-articulation than the boys. This is not surprising since girls are known to have an earlier maturation of motor skills in general and speech articulation in particular (Smith and Zelanik, 2004). It is also in line with the previous study of non speech oral motor function of the same material where boys were more negatively affected by tonsillar hypertrophy (Lundeborg et al. 2009).

The present study had a relatively large drop-out of $30 \%$ of the invited families before enrolment in the study, which was probably caused by the randomization method according to Zelen (Zelen, 1981) where the patients are randomized before contacted about surgery. Since it dealt with relatively small children several parents did not want their child to be exposed to more visits than needed for the surgery.

The relatively low age and narrow age-span of the participants is probably the explanation of why a number of them did not complete all tasks. Before surgery they had never met the person collecting the speech material and the recordings were made in a non-familiar setting. When they came back for the post-operative assessment they were more familiar with the 
procedure and the milieu. Several of the recordings, especially those from the study groups' pre-operative assessment, could not be analyzed acoustically since the children's voice use deviated (for example in whispering or shouting).

The procedure of the acoustic analyses of the /s/-production was selected with regard to the low age of the participating children. When analysing the speech spectrum of small children, spectral clarity is often blurred compared to adult speech, thus obstructing visual interpretations related to intensity. An easy and robust measure regarding the location of the spectral peak is the LTAS analyses used in the present study.

The timing of postoperative assessments in studies evaluating tonsil surgery varies from one month up to one year. The timing chosen in this study is the most common when assessing physiological changes after tonsil surgery ( Flanary, V.A., 2003; Mitchell, R.B., Kelly J., 2004).

In the present study both perceptual ratings and acoustic measures were used. A significant, but rather weak (rho - 0,405 ), correlation was found between the perceptual rating of /s/production and spectral peak locations indicating the perceptual relevance of the spectral peak.

\section{Conclusion}

Children with tonsillar hypertrophy are affected regarding /s/-articulation and differ significantly from controls. Six months post surgery speech production is better, but not enough to match controls. Total tonsillectomy did not give better result on /s/-articulation than tonsillotomy. 


\section{References}

Abbs, J. H. and Gracco, V. L. (1984). Control of complex motor gestures: Orofacial muscle responses to load perturbations of lip during speech. Journal of Neurophysiology, 51(4), 705-723.

Ahlqvist-Rastad, J., Hultcrantz, E. and Svanholm, H. (1988). Children with tonsillar obstruction: Indications for and efficacy of tonsillectomy. Acta Paediatrica Scandinavia, 77(6), 831-835.

Anand, A., Vileda, R. J. and Linde Guarisco, J. (2005). Intracapsular versus standard tonsillectomy: Review of literature. Journal of Louisiana State Medical society, 157, 259-261.

Behlfelt, K., Linder-Aronsson, S., McWilliam, J., Neander, P. and Laage-Hellman, J. (1990). Cranio-facial morphology in children with and without enlarged tonsils European Journal of Orthodontics, 12, 233-243.

Daniloff, R. G., Wilcox, K. and Stephens, M. I. (1980). An acoustic-articulatory description of children's defective s productions. Journal of Communication Disorders, 13(5), 347-363.

Densert, O., Desai, H., Eliasson, A., Frederiksen, L., Andersson, D., Olaison, J. and Widmark, C. (2001). Tonsillotomy in children with tonsillar hypertrophy. Acta Otolaryngologica, 121(7), 854-858.

Ericsson, E., Graf, J. and Hultcrantz, E. (2006). Pediatric Tonsillotomy with Radiofrequency Technique: Long-term Follow-Up The Laryngoscope, 118, 1851-1857.

Flanary, V.A. (2003) Long term effect of adenotonsillectomy on quality of life in pediatric patients. The Laryngoscope, 113, 1639-1644.

Forrest, K. (2002). Are oral-motor exercises useful in the treatment of phonologicalarticulatory disorders? Seminars in Speech and Language, 23(1), 15-26.

Hultcrantz, E., Linder, A. and Markström, A. (2005). Long term effects of intracapsular partial tonsillectomy (tonsillotomy) compared with full tonsillectomy. International Journal of Paediatric Otorhinolaryngology, 69, 463-469.

Jongman, A., Wayland, R. and Wong, S. (2000). Acoustic characteristics of English fricatives. Journal of the Acoustic Society of America, 108(3 Pt 1), 1252-1263.

Koempel, J. A., Solares, C. A. and Koltai, P. J. (2006). The evolution of tonsil surgery and rethinking the surgical approach to obstructive sleep-disordered breathing in children. . The Journal of Laryngology and Otology 120, 993-1000.

Ladefoged, P., and Maddieson, I. (1996). The sounds of the world's languages Oxford.

Laine, T. (1987). Associations between articulatory disorders in speech and occlusal anomalies. European Journal of Orthodontics, 9(2), 144-150.

Lee, A. S. Y., Whitehill, T. L., Ciocca, V. and Samman, N. (2002). Acoustic and perceptual analysis of the sibilant sound s before and after orthognatic surgery. Journal of Oral Maxillofacial surgery, 60, 364-372.

Lindblad, P. (1980). Svenskans sje- och tje-ljud i ett allmänfonetiskt perspektiv ( Some Swedish sibilants). Lund: LiberLäromedelGleerup.

Lindblad, P., and Lundqvist, S. (1996). The production of some Swedish coronals. Stockholm: Department of speech, music and hearing.

Lindblom, B. (1990). Explaining phonetic variation; a sketch of the H\&H theory. In A. W. J. Hardcastle and A. Marchal (Eds.), Speech production and speech modelling . Dordrecht: Kluwer Academic, (pp. 403-430). 
Lofstrand-Tidestrom, B. and Hultcrantz, E. (2009). Development of craniofacial and dental arch morphology in relation to sleep disordered breathing from 4 to 12 years. Effects of adenotonsillar surgery., International Journal of Paediatric Otorhinolaryngology 74(2), 137-143.

Lofstrand-Tidestrom, B., Thilander, B., Ahlqvist-Rastad, J., Jakobsson, O. and Hultcrantz, E. (1999). Breathing obstruction in relation to craniofacial and dental arch morphology in 4-year-old children. European Journal of Orthodontics, 21(4), 323-332.

Lohmander, A., and Olsson, M. (2004). Methodology for perceptual assessment of speech in patients with cleft palate: a critical review of the literature. Cleft Palate Craniofacial Journal, 4l(1), 64-70.

Lundeborg, I., and McAllister, A. (2007). Treatment with a combination of intra-oral sensory stimulation and electropalatography in a child with severe developmental dyspraxia. Logopedics Phoniatrics Vocology, 32(2), 71-79.

Lundeborg, I., McAllister, A., Graf, J., Ericsson, E., and Hultcrantz, E. (2009). Oral motor dysfunction in children with adenotonsillar hypertrophy-effects of surgery. Logopedics Phoniatrics Vocology, 1-6.

Lundeborg, I., McAllister, A., Samuelsson, C., Ericsson, E., and Hultcrantz, E. (2009). Phonological development in children with obstructive sleep-disordered breathing. Clinical Linguistics \& Phonetics, 23(10), 751-761.

Maryn, Y., Van Lierde, K., De Bodt, M. and Van Cauwenberge, P. (2004). The effects of adenoidectomy and tonsillectomy on speech and nasal resonance. Folia Phoniatrica et Logopaedica, 56(3), 182-191.

Midgley, E. J., Dewey, C., Pryce, K., and Maw, A. R. (2000). The frequency of otitis media with effusion in British pre-school children: a guide for treatment. ALSPAC Study Team. Clinical Otolaryngologoly and Allied Sciences, 25(6), 485-491.

Mitchell, R.B. and Kelly J. (2004) Outcome of adenotonsillectomy for severe obstructive sleep apnea in children. Otolaryngology, Head and Neck Surgery,68, 1375-1379.

Mora, R., Crippa, B., Dellepiane, M. and Jankowska, B. (2007). Effects of adenotonsillectomy on speech spectrum in children. International Journal of Pediatric Otorhinolaryngology, 71, 1299-1304.

Nettebladt, U. (2007).Fonologisk utveckling (Phonological development) In U. Nettebladt \& E.-K. Salameh (Eds.), Språkutveckling och Språkstörning hos barn (Language development and language impairment in children)

(pp. 79). Lund: Studentlitteratur.

Niemi, M., Laaksonen, J.-P., Ojala, S., Aaltonen, O. and Happonen, R.-P. (2006). Effects of transitory lingual nerve impairment on speech: An acoustic study of sibilant sound s. International Journal of oral Maxillofacial Surgery, 35, 920-923.

Nittrouer, S. (1995). Children learn separate aspects of speech production at different rates: Evidence from spectral moments. Journal of the Acoustic Society of America, 97(1), 520-530.

Overby, M., Carrell, T.and Bernthal, J. (2007). Teachers' perceptions of students with speech sound disorders: A quantitative and qualitative analysis. Language Speech and Hearing Services in the Schools, 38(4), 327-341.

Perner and Lang, (1999). Development of theory of mind and executive control. Trends in Cognitive Sciences, 3(9), 337-344.

Pirilä-Parkkinen, K., Pirttiniemi,P., Nieminen, P.,Tolonen, U., Pelttari, U. and Löppönen, H. (2009) Dental arch morphology in children with sleep-disordered breathing. European Journal of Orthodontics 31 160-167

Ruscello, D. M., Stutler, S. S.and Toth, D. (1983). Classroom teachers' attitudes toward children with articulatory disorders. Perceptual and Motor Skills, 57(2), 527-530. 
Salami, A., Jankowska, B., Dellepiane, M., Crippa, B.and Mora, R. (2008). The impact of tonsillectomy with or without adenoidectomy on speech and voice. International Journal of Paediatric Otorhinolaryngology, 72(9), 1377-1384.

Schiff-Myers, N. (1993) Hearing children of deaf parents. In D. Bishop and K. Mogford,. (Eds.) Language development in exceptional circumstances (p.47), Hove: Lawrence Earlbaum ass.

Sederholm, E., McAllister, A., Sundberg and Dahlqvist, J. (1993). Perceptual analysis of child hoarseness using continuous scales. Scandinavian Journal of Logopedics \& Phoniatrics, 18, 73-82.

Sederholm, McAllister, Dahlkvist and Sundberg, (1995) Etiologic factors associated with hoarseness in ten-year-old children. Folia Phoniatrica 47, 262-278)

Smith, A.and Zelanik, H. N. (2004). Development of functional synergies for speech motor coordination in childhood and adolescence. Journal of developmental Psychobiology, 22-33.

Stevens, K.N.(1972). The quantal nature of speech:Evidence from articulatory-acoustic data.

In P.B.Denes and E.E.DavidJr.(Eds.), Human communication:A unified view (51-

66).New York: McGraw Hill.

Williamson, I. G., Dunleavey, J., Bain, J.and Robinson, D. (1994). The natural history of otitis media with effusion-a three-year study of the incidence and prevalence of abnormal tympanograms in four South West Hampshire infant and first schools. The Journal of Laryngology and Otology, 108(11), 930-934.

Witt, P. D., Berry, L. A., Marsh, J. L., Grames, L. M.and Pilgram, T. K. (1996). Speech outcome following palatoplasty in primary school children: Do lay peer observers agree with speech pathologists? Plastic \& Reconstructive Surgery, 98 ( 6), 958-965

Younis, R. T.and Lazar, R. H. (2002). History and current practice of tonsillectomy. The Laryngoscope, 112, 3-5.

Zelen, M. (1981). Alternatives to classic randomized trials. Surgical Clinics of North America, 61(6), 1425-1432.

Öster, A.-M., House, D., Hatzis, A.and Green, P. (2003). Testing a new method for training fricatives using visual maps in the Ortho-Logo-Paedia project (OLP). Phonum, 9, 8992. 